This is an electronic reprint of the original article. This reprint may differ from the original in pagination and typographic detail. Author(s): Pohjanmies, Tähti; Triviño, María; Le tortorec, Eric; Salminen, Hannu; Mönkkönen,
Mikko

Title: $\quad$ Conflicting objectives in production forests pose a challenge for forest management

Year: $\quad 2017$

Version:

Please cite the original version:

Pohjanmies, T., Triviño, M., Le tortorec, E., Salminen, H., \& Mönkkönen, M. (2017).

Conflicting objectives in production forests pose a challenge for forest management.

Ecosystem Services, 28(Part C), 298-310.

https://doi.org/10.1016/j.ecoser.2017.06.018

All material supplied via JYX is protected by copyright and other intellectual property rights, and duplication or sale of all or part of any of the repository collections is not permitted, except that material may be duplicated by you for your research use or educational purposes in electronic or print form. You must obtain permission for any other use. Electronic or print copies may not be offered, whether for sale or otherwise to anyone who is not an authorised user. 


\title{
Conflicting objectives in production forests pose a challenge for forest management
}

Tähti Pohjanmies ${ }^{a}{ }^{*}$ María Triviño $^{a}$, Eric Le Tortorec ${ }^{a}$, Hannu Salminen $^{b}$, Mikko Mönkkönen $^{a}$

\author{
aUniversity of Jyvaskyla, Department of Biological and Environmental Science, P.O. Box 35, FI-40014, \\ University of Jyväskylä, Finland \\ ${ }^{\mathrm{b}}$ Natural Resources Institute Finland (Luke), Eteläranta 55, FI-96300 Rovaniemi, Finland \\ *Corresponding author; telephone: +358407397503, e-mail: tahti.t.pohjanmies@jyu.fi
}

Accepted for publication in Ecosystem Services, doi: 10.1016/j.ecoser.2017.06.018

\begin{abstract}
Conflicts among different ecosystem services have been shown to be common and potentially exacerbated by management interventions. In order to improve the sustainability of natural resource use, the occurrence of these conflicts and the effects that management actions have on them need to be understood. We studied the conflicts between ecosystem services and the potential to solve them by management choices in boreal production forests. Our study area consisted of nearly 30,000 forest stands which were simulated for 50 years into the future under alternative management scenarios. The study included four ecosystem services - timber production, bilberry production, carbon storage, and pest regulation - and one biodiversity conservation objective defined as availability of deadwood resources. We 1) measured the conflicts among each pair of objectives, and 2) identified a compromise solution for each pairwise conflict defined as one which simultaneously minimizes the losses for both objectives. Our results show that conflicts between timber production and other objectives are typical, severe, and difficult to solve, while non-extractive benefits including biodiversity conservation can be more easily reconciled with each other. To mitigate the most severe conflicts in boreal forests, increased diversity in management regimes is required.
\end{abstract}

Keywords: ecosystem service; biodiversity; trade-off; timber production; boreal forest; Finland 


\section{Introduction}

Evaluating ecosystem services, or the diverse benefits people obtain from nature, may produce information that assists ecosystem managers in balancing the multiple, often conflicting, interests that people place on the environment (Albert et al., 2014; Bennett et al., 2009). Critical aspects of these evaluations include the co-occurrence of multiple ecosystem services, their interactions, and the impacts human activities have on their supply. The complexity of the relationships among different ecosystem services, aspects of biodiversity, and social objectives was recognized already in the Millennium Ecosystem Assessment (MEA, 2005), and considerable effort has since gone into conceptualizing and clarifying these processes (e.g. Kremen, 2005; Bennett et al., 2009).

A key first step in improving the sustainability of natural resource use is to identify patterns of trade-offs and synergies among ecosystem services and how they are driven by management interventions. A tradeoff between ecosystem services occurs when the increased utilization of one service leads to a loss in another service, and they may take place at varying spatial and temporal scales (Rodríguez et al., 2006). The Millennium Ecosystem Assessment (MEA, 2005) established that ecosystem management to increase the supply of one ecosystem service may deteriorate the supply of other services, and that these negative trade-offs are particularly common between individual provisioning services and between provisioning and other types of ecosystem services (regulating, supporting, and cultural services). An extreme case is the conversion of natural ecosystems into managed monocultures, but also the extractive use of resources from a (semi-)natural ecosystem may, by altering the structures and functions of the ecosystem, cause more or less persistent changes in other ecosystem services.

Several recent studies have examined the relationships among ecosystem services and the effects of management on their supply in forests, where timber harvesting and other management activities cause changes in ecosystem structures and functions (e.g. Bradford and D'Amato, 2012; Edwards et al., 2014; Brandt et al., 2014). Forests provide many important ecosystem services: they are a source of food and raw materials, provide recreational opportunities, hold cultural meanings, harbor a variety of beneficial organisms, regulate air, soil, and water quality, and play an important role in climate regulation. Even where forest loss is not a major threat, forests are affected by increasing pressures, such as a rising demand for forest biomass, the urgency to utilize forest ecosystems in climate change mitigation, and the need to safeguard biodiversity. Additionally, forests undergo natural disturbances that are expected to intensify in response to global change (Lindner et al., 2010; Seidl et al., 2016). These challenges create multiple objectives for forest management as well as a mounting need to resolve the conflicts among them (Bradford and D'Amato, 2012). 
Boreal forests are extensively used for timber production, but are also a source of many locally and globally important ecosystem services. Earlier studies from boreal forests have shown that conflicts between timber production and other ecosystem services are common (e.g. Gamfeldt et al., 2013; Pohjanmies et al., 2017) and that stand management can affect trade-offs among forest services (Triviño et al., 2015; Zanchi et al., 2014). Specifically, maximizing timber harvests has been found to reduce forests' capacity to provide other services, while less intensive use of timber resources can lead to compromise solutions where intermediate levels of several objectives are maintained (Triviño et al., 2015; Zanchi et al., 2014). However, these impacts may be dependent on the ecosystem services in question and the properties of the forest (Biber et al., 2015). Moreover, few studies have examined the occurrence of conflicts among non-timber benefits from managed forests.

In this study, we study the occurrence and severity of conflicts between ecosystem services in a large production forest in Finland. Earlier studies in this landscape have shown that conventional, intensive forest management may cause severe trade-offs between timber production and biodiversity (Mönkkönen et al., 2014), climate regulation (Triviño et al., 2015), and forest collectables (Peura et al., 2016). Here, we measure the conflicts between timber production and non-timber forest benefits but also among nontimber benefits. We thus aim to resolve whether the most severe conflicts are those between a provisioning service (here, timber production) and other objectives, while non-extractive benefits including biodiversity conservation can be more easily reconciled with each other.

Earlier work conducted in our study area has also shown that considerable benefits in terms of biodiversity and ecosystem services can be gained by diversifying forest management regimes and optimizing their application across the landscape (Mönkkönen et al., 2014; Triviño et al., 2015). In these studies, forest management has been optimized at the scale of the entire landscape, recognizing the possibility that only some forest stands can produce high levels of several objectives simultaneously, while some can be disproportionally good for targeting a single objective. Optimal management across the landscape may thus be a combination of 'land-sharing' and 'land-sparing' strategies (e.g. Triviño et al., 2015), the former referring to a high supply of multiple ecosystem services from the same stand and the latter to prioritization of a single ecosystem service in a stand (e.g. Edwards et al., 2014; Maskell et al., 2013). In our study, we focus on 'land-sharing' strategies and measure the severity of conflicts among pairs of objectives in each individual forest stand. We thus explore how achievable 'land-sharing' strategies are at the stand level. The achievability of good 'land-sharing' solutions at the stand level provides additional information on the severity of the pairwise conflicts and is important from a practical point of view. First, as a stand is the basic operational unit of practical forestry (Mäkelä and Pekkarinen, 2004), the stand level is the most relevant for forest managers. Second, management plans that allow for single-objective prioritization in parts of the target area may be misguided if demand for the objectives is not considered, that is, 
prioritization of an objective may be assigned to an area where there is no demand for it or vice versa. For example, while it may make little difference exactly where the benefits are generated in the case of some ecosystem services such as carbon storage, some ecosystem services may have very local demand (e.g. recreation, forest collectables, and some regulating services). Finally, minimizing trade-offs in every parcel of the landscape may help protect those objectives that are affected by the quality of neighboring stands; particularly, conservation of biodiversity that requires both patches of high-quality habitat and a relatively good-quality matrix (Kremen, 2015).

Our study includes five forest management objectives: four ecosystem services (timber production, bilberry production, carbon storage, and pest regulation) and one biodiversity conservation objective, defined as availability of deadwood resources. First, we measure the supply of each objective and the conflicts among all pairs of objectives under alternative forest management regimes. Second, we identify a compromise management solution for each pairwise conflict, defined as one which simultaneously minimizes the losses in both objectives. Finally, we examine the distributions of alternative forest management regimes among the compromise solutions and infer management recommendations for maintaining diverse benefits. Specifically, we address the following questions: 1) How strong are the conflicts between all pairs of objectives? 2) How efficiently can the pairwise conflicts be solved by optimizing management? 3) What kind of forest management may be required to secure high levels of multiple ecosystem services and biodiversity?

\section{Materials and methods}

\subsection{Forest data and simulations}

Our study area is a typical Finnish production forest landscape located in central Finland with forest covering the majority of the land and the rest consisting of a mosaic of lakes, peat lands, small settlements, and cultivated fields (Figure 1). The total forest area is $431 \mathrm{~km}^{2}$ and consists of nearly 30,000 individual stands. The stands are dominated by pine (Pinus sylvestris), spruce (Picea abies), birch (Betula pendula and Betula pubescens), or a mix of the four species. Most of the landscape has been under active forest management for several decades, and this is reflected in the current condition of the forest. Specifically, the age distribution of the stands is asymmetric with over $30 \%$ of the stands being younger than 20 years, over $60 \%$ younger than 50 years, and only about $5 \%$ older than 100 years.

In order to account for the long-term ability of the forest to provide ecosystem services, we simulated the development of the stands under different management regimes for 50 years into the future. The initial stand-level data was compiled from forest inventory data administered by the Finnish Forest Centre 
(Finnish Forest Centre, 2016) to include the variables needed for the simulations, e.g. basal area of trees, tree species composition, ages of tree cohorts, and site fertility. Forest growth simulations were implemented with the MOTTI stand simulator (Hynynen et al., 2002; Salminen et al., 2005). MOTTI predicts the development of a stand based on its initial characteristics and the forestry operations applied during the simulation. In MOTTI, a set of empirical-statistical models are integrated into software that predicts the growth and mortality of trees on the basis of the quality of the site, the growth potential of the tree and the competition effects imposed by other trees. We simulated each stand under seven alternative management regimes that form a gradient of management intensity (Table 1): the recommended regime for private forestry in Finland or 'business-as-usual' (Hyvän metsänhoidon suositukset, 2006); the recommended regime modified by increased green tree retention, postponed final harvesting (two options), or no thinnings (two options); and set-aside. The recommended regime and the set-aside represent the extremes among the alternatives, while the other five regimes correspond to currently implemented strategies to mitigate biodiversity loss in commercial forests in Finland (Mönkkönen et al., 2014). Postponing the final harvesting, refraining from thinnings, and applying green tree retention are intended to increase the amount of deadwood and enhance the structural diversity within the forest. In general, they may lead to losses in harvest revenues due to delayed harvests (postponed final harvesting), reduced harvest volumes (green tree retention) or smaller sized trees (no thinnings). The simulation period was divided into 5-year time steps, giving a total of 11 model runs. For more details on the forest growth simulations, see Appendix A. 


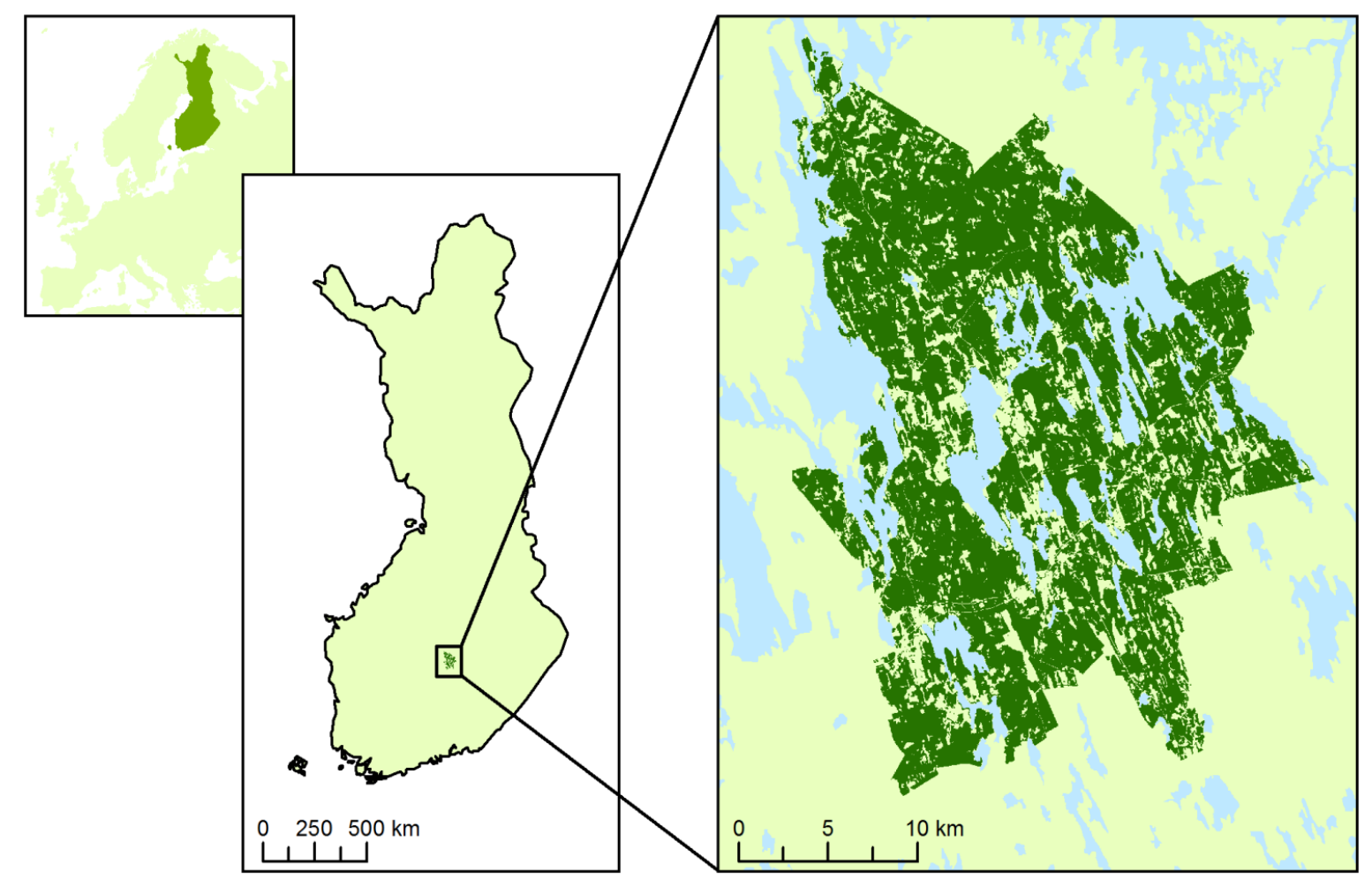

Figure 1. Map showing the location of the study area in Finland (in dark green color).

Table 1. The seven alternative management regimes used in the forest growth simulations. The development of each stand in the study area was simulated under all of the alternative regimes (adapted from Mönkkönen et al., 2014).

\begin{tabular}{|c|c|c|}
\hline Management regime & Acronym & Description \\
\hline Business-as-usual & BAU & $\begin{array}{l}\text { Recommended management: average rotation length } 80 \text { years; } \\
\text { site preparation, planting or seedling trees; } 1-3 \text { thinnings; final } \\
\text { harvest with green tree retention level of } 5 \text { trees/ha. }\end{array}$ \\
\hline Green tree retention & GTR30 & BAU with 30 green trees retained/ha at final harvest. \\
\hline Extended rotation (10 years) & EXT10 & $\begin{array}{l}\text { BAU with final harvest postponed by } 10 \text { years (i.e. average rotation } \\
\text { length } 90 \text { years). }\end{array}$ \\
\hline Extended rotation (30 years) & EXT30 & $\begin{array}{l}\text { BAU with final harvest postponed by } \geq 30 \text { years (i.e. average } \\
\text { rotation length } 115 \text { years). }\end{array}$ \\
\hline $\begin{array}{l}\text { No thinnings (minimum final } \\
\text { harvest threshold values) }\end{array}$ & NTSR & $\begin{array}{l}\text { BAU with no thinnings \& final harvest adjusted so that rotation } \\
\text { does not prolong: average rotation length } 77 \text { years. }\end{array}$ \\
\hline $\begin{array}{l}\text { No thinnings (final harvest } \\
\text { threshold values as in BAU) }\end{array}$ & NTLR & $\begin{array}{l}\text { BAU with no thinning \& final harvest allowed to be delayed: } \\
\text { average rotation length } 86 \text { years. }\end{array}$ \\
\hline Set-aside & SA & No silvicultural operations, no harvest. \\
\hline
\end{tabular}

\subsection{Ecosystem service and biodiversity indicators}


We measured the provision of ecosystem services and biodiversity under each management regime. We considered four ecosystem services: timber production, bilberry production, carbon storage, and pest regulation. This selection represents all ecosystem service categories (provisioning, regulating, and cultural) and a range of spatial scales in which the benefits are realized (local - global). The objective of biodiversity conservation was measured as the availability of deadwood resources.

As timber production is the primary source of revenue to the forest owner, it is usually the main focus of forest management. Timber production was measured as the total amount of harvested commercial timber. This consisted of both pulpwood and saw logs collected during the first and intermediate thinnings as well as final harvesting, as applied in the forest growth simulations. Harvesting of energy wood (e.g. stumps and branches) was not considered.

Bilberry (Vaccinium myrtillus) is one of the economically most important wild berries in Finland and bilberry picking has a provisioning as well as a recreational function (Vaara et al., 2013). We used the data on bilberry yield estimates from Peura et al. (2016), where bilberry production was estimated using the models of Miina et al. (2009). Carbon storage by boreal forests has an important role in global climate regulation and maintaining this function is essential for climate change mitigation (Moen et al., 2014; Pan et al., 2011). We used the carbon storage data from Triviño et al. (2015), where the amount of carbon stored in a stand was calculated as the amount of carbon in living trees, deadwood, and extracted timber. We used habitat availability for three-toed woodpecker (Picoides tridactylus) as a proxy for pest regulation, as the species is an important natural predator of bark beetles and has been found to have a potentially significant role in regulating bark beetle outbreaks (Fayt et al., 2005). Additionally, three-toed woodpecker is suggested to be an indicator of bird species richness in Finnish forests (Pakkala, 2012). Estimates of habitat availability for three-toed woodpecker were taken from Mönkkönen et al. (2014), where habitat availability was calculated with a model that estimates a habitat suitability index related to the probability of presence of the species based on stand characteristics (Mönkkönen et al., 2014).

Availability of deadwood resources was selected as the measure of the biodiversity objective given the strong evidence of deadwood as an indicator of broad biodiversity (Gao et al., 2015), and because loss of deadwood is estimated to be the most common cause of species endangerment in Finnish forests (Rassi et al., 2010; Tikkanen et al., 2006). Availability of deadwood was described as the product of its total volume and its diversity, which was measured as the Simpson diversity of different deadwood types (different tree species and decay stages). By taking into account both the volume and the diversity of deadwood, the measure is more likely to be a genuine indicator of deadwood dependent biodiversity (Lassauce et al., 2011). For further details on the calculations of the ecosystem service and biodiversity indicators, see Appendix B. 
Timber production was measured across the entire simulation period, i.e. as the total amount of harvested timber over the 50 years. All of the other measures were calculated for each time step of the simulation period and then averaged across time. These average values were used in the analyses.

\subsection{Measures of conflicts and compromise solutions}

We measured the pairwise conflicts between the objectives listed in the previous section using the methodology of Mazziotta et al. (2017). This method describes a pairwise conflict between objectives $a$ and $b$ as their tolerance of each other. Tolerance is measured as the proportion of objective $a$ that can be achieved while objective $b$ is maximized, and vice versa (Figure 2A). The method thus results in two values, $a$ 's tolerance of $b$ and $b^{\prime}$ s tolerance of $a$, recognizing that the conflicts may be asymmetric as management actions may affect different objectives in different, even opposite ways (Mazziotta et al., 2017). The conflict between objectives $a$ and $b$ is asymmetric if, for example, maximizing $a$ leads to a substantial loss in $b$, but maximizing $b$ leads only to a small loss in $a$. We measured the pairwise conflicts among all five objectives, resulting in $20(5 \times 4)$ pairwise tolerance indices.

For example, to calculate timber production's tolerance of bilberry production, we identified the forest management regime out of the seven alternatives that maximizes bilberry production and compared the amount of timber production under this regime to timber production's potential maximum. The tolerance index is thus the percentage of maximal timber production (achieved under timber-focused management) that is achieved under bilberry-focused management. If this percentage is low, the conflict between the two objectives is severe.

Following the methodology of Mazziotta et al. (2017), the conflict between two objectives may be solved by finding a compromise solution: an optimal management plan that simultaneously minimizes the losses in both objectives when compared to their maximal values (Figure 2B). We implemented this method to identify the compromise management option for each stand and for each pair of objectives. We then compared the values achieved under the compromise management to the maximal values of the objectives.

For each objective, we thus obtained two metrics: the value when another objective was maximized, and the value under compromise management with another objective. Both were expressed as percentage of the maximal achievable value. In order to evaluate conflict severity we obtained the frequency distribution of these conflict measurements by pooling information from all stands. Additionally, we examined the distributions of the management regimes that were identified as providing the compromise solutions. 

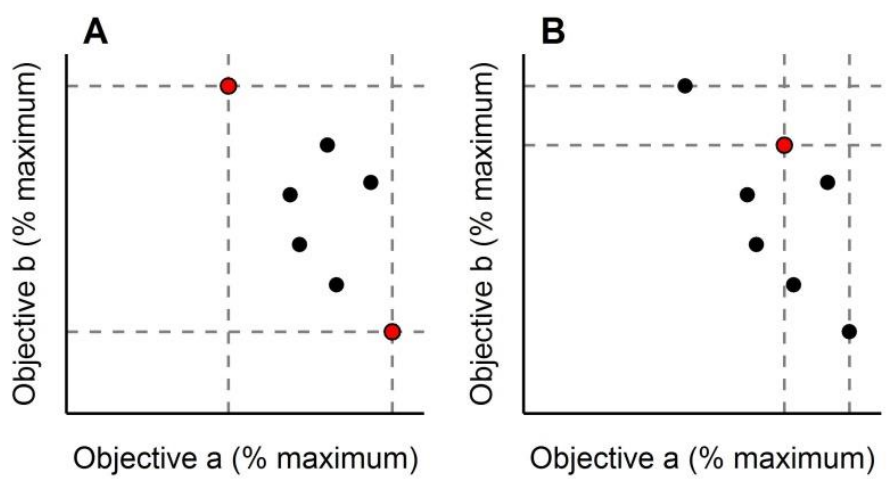

Figure 2. Illustration of the method used to calculate pairwise tolerance indices and to identify compromise solutions for pairs of objectives. The points show the outcomes of two objectives ( $a$ and $b$ ) under different management scenarios. The two red points in (A) show the solutions that maximize the two objectives, respectively. The ratio between the dashed vertical lines measures objective $a$ 's tolerance of objective $b$, and the ratio between the dashed horizontal lines measures objective $b$ 's tolerance of objective $a$. The single red point in (B) shows the compromise outcome, i.e. the solution that minimizes the losses in both objectives when compared to their maximal values. Here, the ratios between the dashed vertical and horizontal lines measure the goodness of the compromise solution in terms of objective $a$ and $b$, respectively.

\section{Results}

\subsection{Ecosystem service potential of the landscape}

The forest stands in the study area were highly variable in the potential to provide the measured objectives (Figure 3). The distributions of the maximal values of all of the objectives were more or less skewed towards low values, but particularly so were the values of the biodiversity objective of deadwood availability. This is likely due to the history of the landscape as production forest (cf. Siitonen, 2001). 

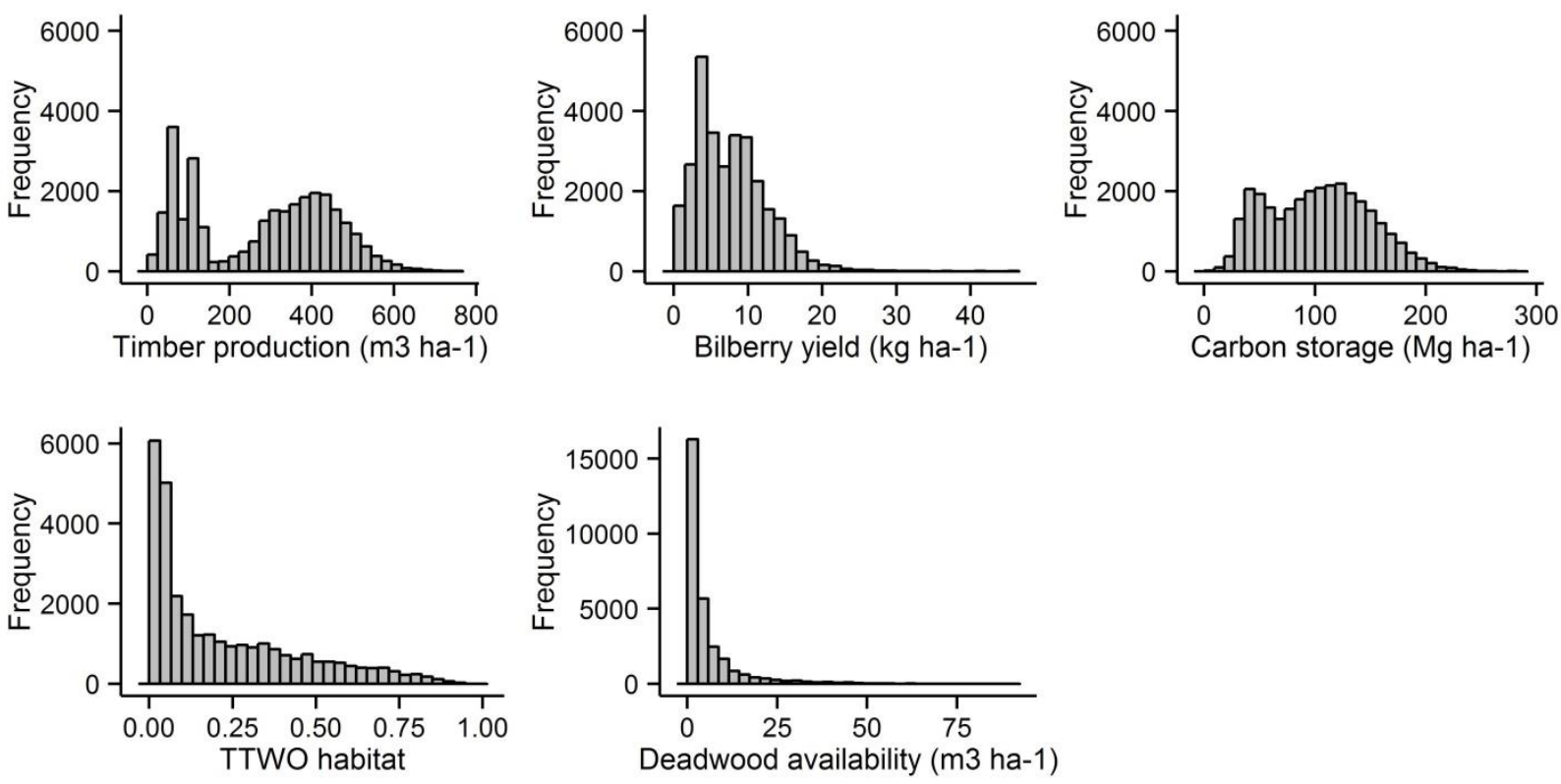

Figure 3. Distributions of the maximal achievable stand-level values of the five objectives. The values for timber production show the total amount of harvested timber over the 50-year simulation period. The values for the other four measures show the average yearly value over the simulation period. The acronym TTWO refers to three-toed woodpecker. We note that deadwood availability was measured as the volume of deadwood multiplied by its diversity; its unit is thus $\mathrm{m}^{3} \mathrm{ha}^{-1}$ but the values have been weighed by the diversity index and as such do not tell the true volume of deadwood in the stand.

\subsection{Strength of the pairwise conflicts}

There was high variability in the strength of the conflicts among pairs of objectives. A first indicator of the severity of the conflicts was the compatibility of optimal management regimes among pairs of objectives, i.e. the share of stands where both objectives could be maximized by the same management regime. This share of stands was low when one of the objectives in the pair was timber production $(1.4 \%-31.2 \%$ of stands; Figure 4$)$ or bilberry production ( $25.1 \%-34.7 \%$ of stands; Figure 4$)$. For all other pairs the same management regime was the most favorable in a majority of stands $(80.5 \%-90.8 \%$; Figure 4$)$.

When the same management regime could maximize both objectives in a given stand, there was no conflict between them in that stand. To focus on the cases where the objectives were not completely compatible and could thus potentially be reconciled by management choices, we report here the pairwise tolerance indices and the compromise solutions only for those stands where the two objectives required different management regimes to reach their maximal values. This means $9.2 \%-98.6 \%$ of the stands, depending on the pair of objectives (Figure 4). The results for the full set of stands are reported in Appendix C. 


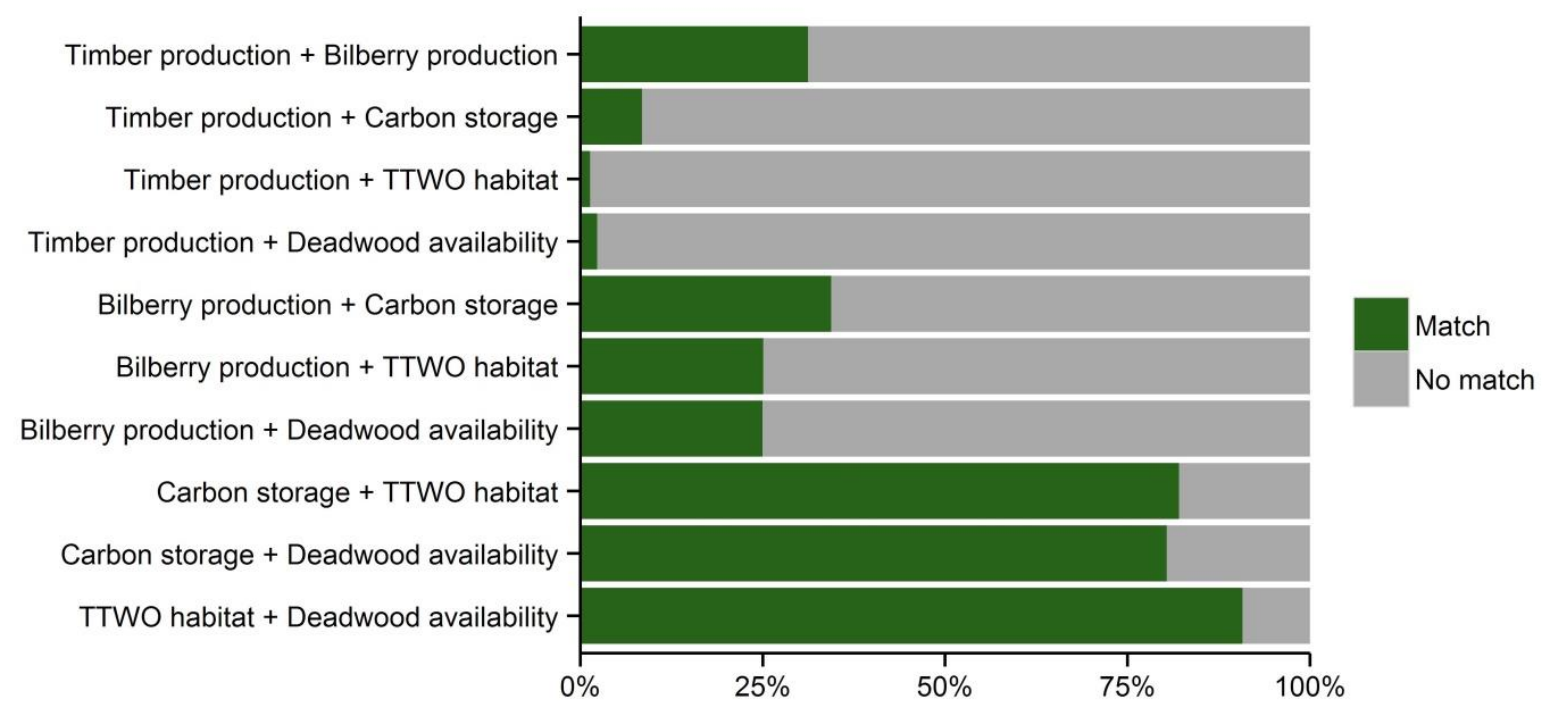

Figure 4. Proportions of stands where two objectives were ('Match') or were not ('No match') maximized by the same management regime. The acronym TTWO refers to three-toed woodpecker.

Measured by the pairwise tolerance indices, timber production showed the greatest level of conflict with the rest of the evaluated objectives: very low values of harvested timber were reached as compared to its achievable maximum when another objective was maximized (median values of $0 \%-17.3 \%$; Figure 5A-D). Likewise, maximizing timber production led to losses in the other objectives as shown by their low tolerances of timber production (median values ranging between $39.3 \%$ and $83.6 \%$; Figure $5 \mathrm{~A}-\mathrm{D}$ ). The second strongest conflict was between three-toed woodpecker habitat and bilberry production (median value for three-toed woodpecker habitat when bilberry production was maximized was $26.2 \%$, Figure $5 F$ ). The tolerance indices for the rest of the pairs were not notably higher (45.7\% - 82.4\%; Figure $5 \mathrm{E}$, G-J), but, as explained above, these values correspond only to a small proportion of the stands, whereas in a majority of stands the tolerance indices for these pairs were 100\% (Figure C1 in Appendix C).

Some of the observed conflicts between the objectives could be mitigated by finding compromise solutions. In particular, the compromise solutions were very favorable for timber: the median values of timber under the compromise solutions were $100 \%$ for all pairs (Figure 6A-D). However, when compromised with timber production, the solutions were notably less favorable for the other objectives as they could reach values that were only some percentage points higher than their respective tolerances of timber production (median values of $48.7 \%-88.7 \%$; Figure $6 \mathrm{~A}-\mathrm{D}$ ).

The compromise solutions were slightly more balanced for the second most conflicting pairs, i.e. those involving bilberry production, as here both objectives reached median values ranging between $80.3 \%$ and $100 \%$ (Figure $6 \mathrm{E}-\mathrm{G}$ ). For the rest of the pairs among carbon storage, three-toed woodpecker habitat, and 
deadwood availability, which had shown moderately strong conflicts, the compromise solutions were outstandingly good (median values of $96.5 \%$ - 100\%; Figure $6 \mathrm{H}-\mathrm{J}$ ). For example, when carbon storage was maximized, three-toed woodpecker habitat could reach only $52.0 \%$ of its maximum (Figure $5 \mathrm{I}$ ). Under the compromise solution, three-toed woodpecker habitat could reach $100 \%$ of its maximum while at the same time $97.0 \%$ of maximal carbon storage was maintained (Figure 61 ).
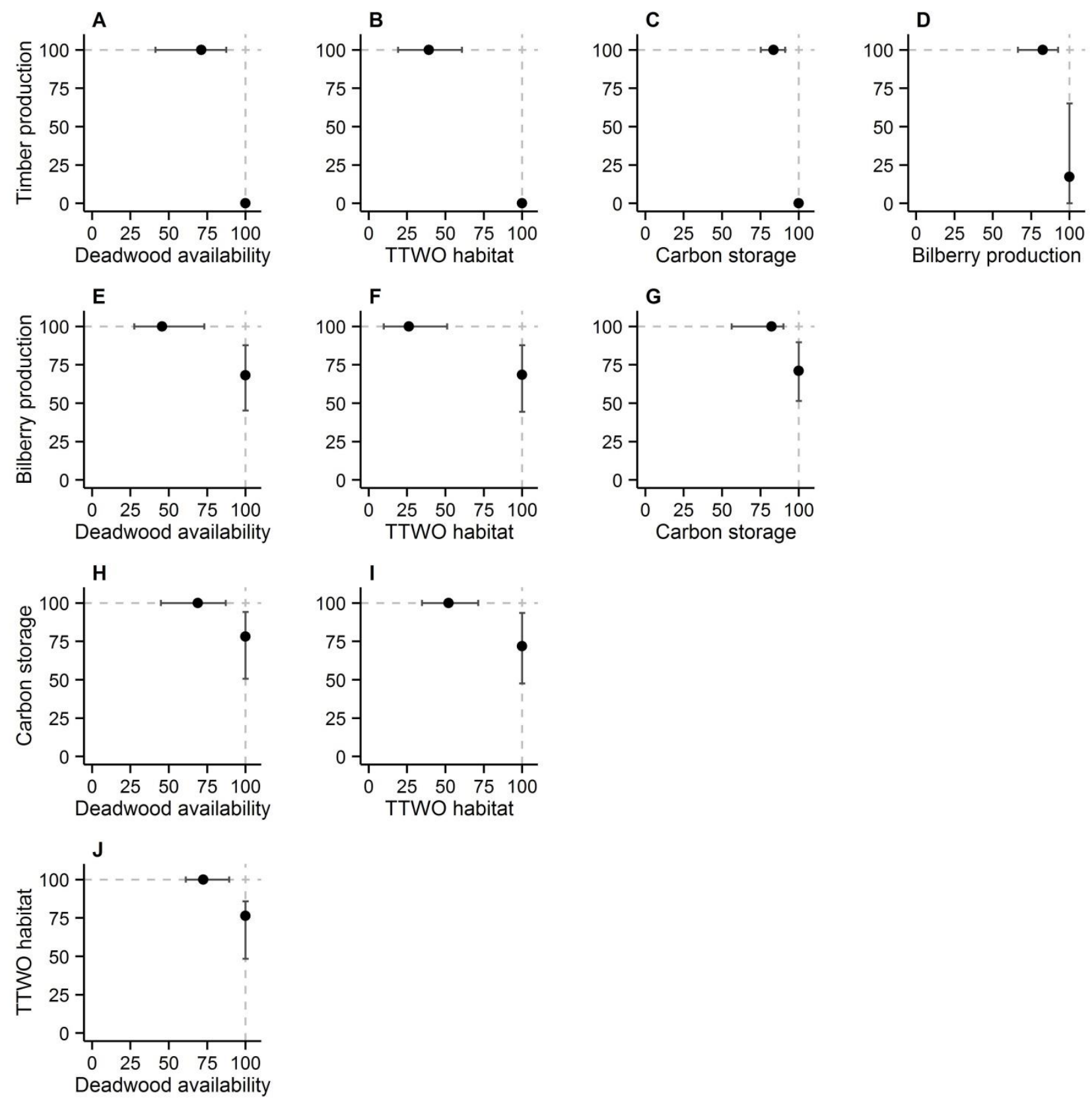

Figure 5. Pairwise tolerance indices for all pairs of objectives. The black points show the median values and the error bars the second and third quartiles of stand-level values. The tolerance indices are expressed as percentage of the maximal achievable value; units on all axes are thus percentages (\%). Dashed grey lines have been added to all plots at $y=100 \%$ and $x=100 \%$ for graphical comparison. Shown are the results for 
the stands where both objectives were not maximized by the same management regime. The acronym TTWO refers to three-toed woodpecker.
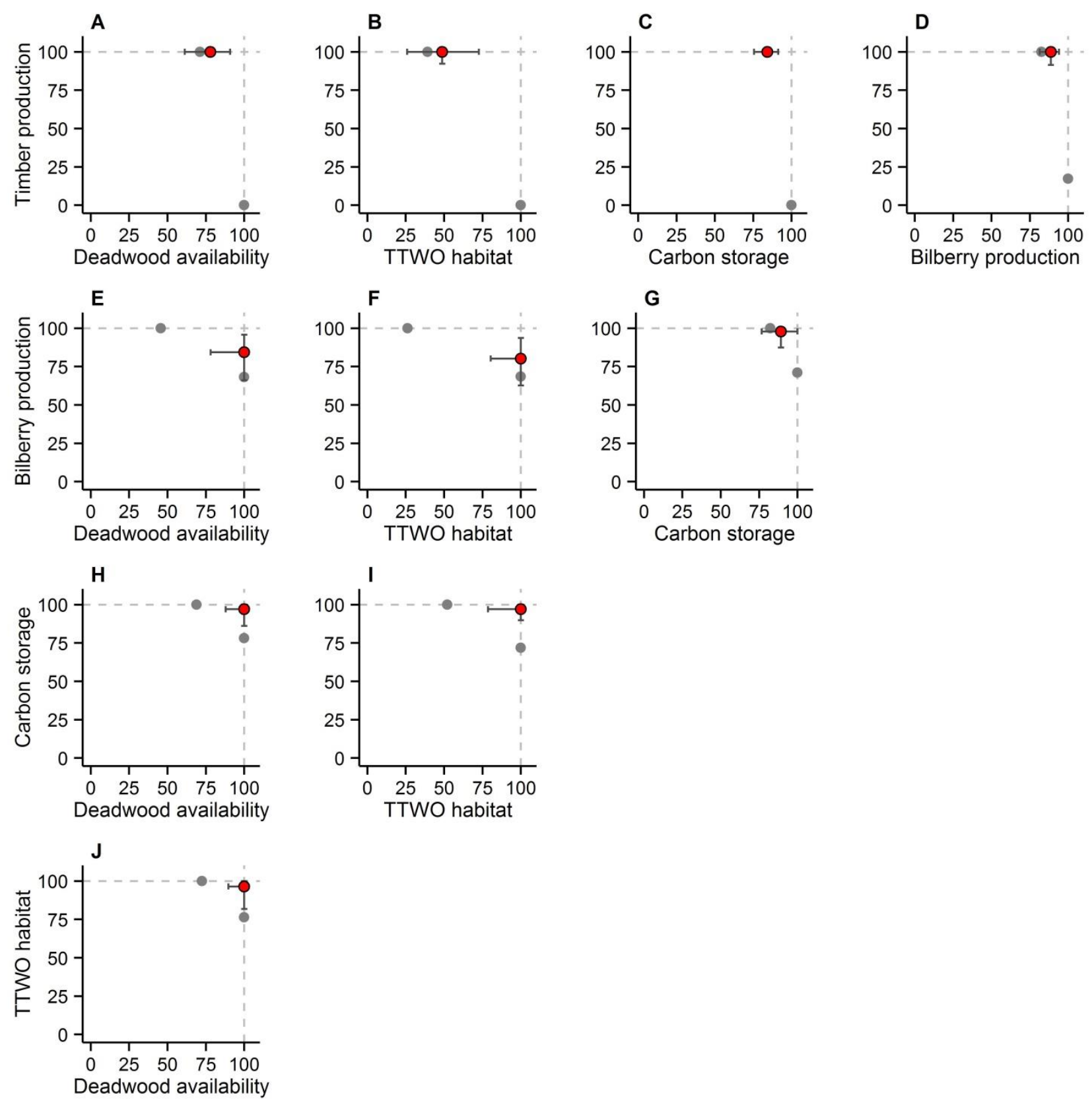

Figure 6. Compromise solutions for all pairs of objectives. In each plot, the red point shows the median value and the error bars the second and third quartiles of stand-level values of the two objectives under the compromise solution. The two grey points show the median values of the tolerance indices for comparison (same as the black points in Figure 4). The closer to the point $(100,100)$ the compromise is, the better it is in terms of the two objectives. Units on all axes are percentages (\%). Dashed grey lines have been added to all plots at $y=100 \%$ and $x=100 \%$ for graphical comparison. Shown are the results for the stands where both objectives were not maximized by the same management regime. The percentage at the bottom corner of each plot shows the proportion of the entire set of stands meeting this condition. The acronym TTWO refers to three-toed woodpecker. 


\subsection{Management regimes}

Identifying a single management regime as the compromise solution for two objectives was not always possible due to the fact that two or more management options could lead to similar outcomes. This was usually because, despite being different by definition, in practice they included the same combination of management actions (thinnings and final harvest) during the 50 year simulation period. Some patterns in the compromise solutions between pairs of objectives nevertheless stood out clearly. When timber production was one of the two objectives, the compromise regimes were more or less evenly distributed among 'business-as-usual' (the regime following current Finnish stand management recommendations) and the modified versions of 'business-as-usual' (increased green tree retention, postponed final harvesting, or no thinnings) with proportions ranging between $4 \%-35 \%$ (Figure 7). For the pairs not including timber production, the solutions were dominated by the set-aside option with set-aside identified as the compromise regime in $46 \%-95 \%$ of the stands (Figure 7 ).

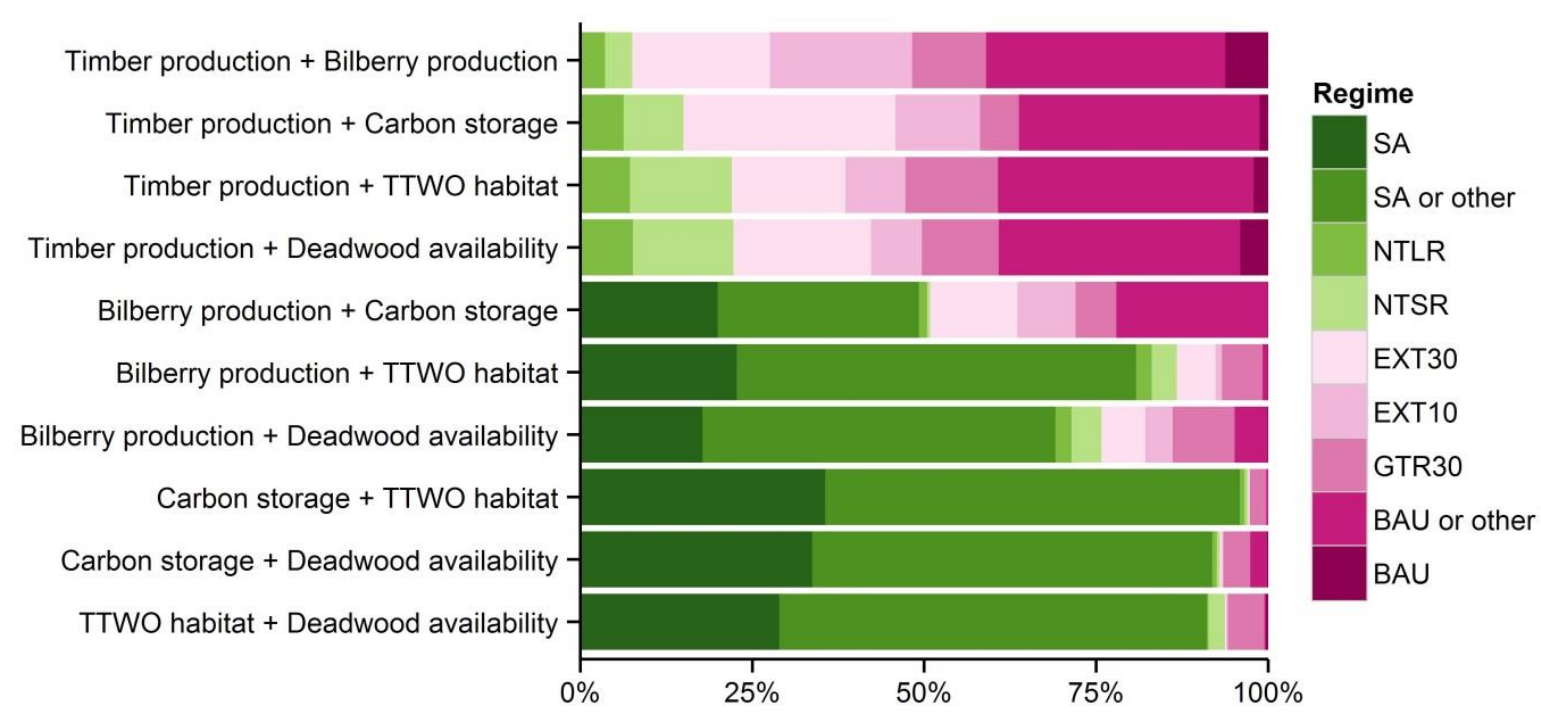

Figure 7. Distribution of optimal management regimes (compromise solutions) among stands for different pairs of objectives. The regime acronyms stand for: SA - set-aside; NTLR and NTSR - no thinnings; EXT10 and EXT30 - extended rotation time; GTR30 - green tree retention; BAU - business-as-usual. More details are given in Table 1. 'SA or other' refers to cases where set-aside and one or more regimes gave equal outcomes, and 'BAU or other' or business-as-usual and one or more regimes gave equal outcomes (see text). The acronym TTWO refers to three-toed woodpecker.

\section{Discussion}


In this study, we compared the outcomes of forest management targeting a single objective and management aiming to reconcile two objectives. We measured the supply of each objective when another objective was maximized ('tolerance') and when management was optimized to simultaneously minimize the losses in both objectives ('compromise solution'). Both measures characterize the conflict between the two objectives. We found severe conflicts between timber production and the other objectives, moderate conflicts between bilberry production and the other objectives, and weak conflicts among carbon storage, pest regulation, and biodiversity conservation. Compromise management could mitigate the conflicts, but to varying extents.

Based on previous findings of trade-offs between timber production and other forest benefits (e.g. Duncker et al., 2012; Gamfeldt et al., 2013; Schwenk et al., 2012), we expected the conflicts between timber production and other objectives to be the most severe, and this was indeed the case. When any of the nontimber objectives were prioritized, timber production reached very low values, and when timber production was prioritized, the other objectives reached low (three-toed woodpecker habitat, deadwood availability) to moderate values (bilberry production, carbon storage) (Figure 5A-D). As generalized by the MEA (2005), intensive management for a single provisioning service changes the ecosystem and results in losses in other ecosystem services. Out of the non-timber objectives, bilberry production was the most compatible with timber production (Figure 5D). Other studies have also found non-timber forest products like berries to benefit from stand management activities under certain conditions (Clason et al., 2008; DeMiguel et al., 2014; Nybakken et al., 2013). The high tolerance of carbon storage to timber production (Figure 5C), then again, was likely affected by the calculation method for this objective. Carbon fixed in the biomass of extracted timber was one of the carbon pools included into the measure of total carbon storage, producing values that may favor timber-oriented management unrealistically as the fate of this carbon is not actually known. The fate of carbon fixed in harvested wood products may critically affect whether production forests act as carbon sources or sinks (Liski et al., 2001). Like timber production, bilberry production was in strong conflict particularly with three-toed woodpecker habitat and deadwood availability (Figure 5E-F). Conversely, carbon storage, three-toed woodpecker habitat, and deadwood availability were all highly compatible with each other (Figure $5 \mathrm{H}-\mathrm{J}$ ).

The compromise solutions showed the most prominent improvements in terms of timber production. Timber production reached very low levels when other objectives were prioritized (Figure 5A-D) but very high levels under the compromise solutions (Figure 6A-D). However, these results should not be misinterpreted as indicating an efficient solution to the conflict, because there was notable asymmetry in the goodness of the compromise solutions between objectives. The levels of the other objectives under the compromise solutions were only slightly higher than their tolerances of timber production whereas timber production was at or close to its maximum (Figure 6A-D), meaning that the compromise solutions were, in 
fact, only slightly different from prioritizing timber production. The non-timber objectives could be reconciled with each other with more balanced outcomes, with particularly carbon storage, three-toed woodpecker habitat, and deadwood availability all reaching very high levels (Figure 6H-J). The conflicts between timber production and the other objectives were thus not only the most severe but also the most difficult to solve.

It should be noted that the results of our study are influenced by the selection of management regimes included in the study. In particular, timber production's low tolerance of carbon storage, three-toed woodpecker habitat, and deadwood availability is probably for the most part due to the predominance of the set-aside regime in maximizing these objectives. In this regime, by definition, the stand is not harvested at all and timber production is thus zero. Consequently, when timber production was among the objectives, the set-aside regime was not identified as the compromise solution in any of the stands, and timber production reached much higher levels. The low values of the non-timber objectives under the compromise solutions suggest that in most stands the management regimes other than set-aside are more or less equally bad in terms of these objectives, limiting the possibilities to find efficient compromises and true 'land-sharing' solutions. This is further indicated by the high proportion of the set-aside option as the management to solve the conflicts between bilberry production and other objectives.

Another important consideration is that the measures of the conflicts used here are calculated based on the maximal achievable level of each objective under the alternative management regimes over the 50-year simulation period. They are thus conditional to what is achievable under these management regimes and over this time period. For example, the maximal total volume of deadwood as predicted by our simulations was on average $10 \mathrm{~m}^{3} \mathrm{ha}^{-1}$, which seems very low as there may be manifold amounts of deadwood in natural old-growth forests (Siitonen, 2001). If the simulation time had been longer and the forests had had more time to recover from their past as production forest, even higher maximal values could have been achievable for deadwood availability and the other non-timber objectives, and as a consequence the conflicts between them and timber production would have potentially appeared even more intense. In short, in most of the stands in our study area, comparatively high levels of bilberry production, carbon storage, three-toed woodpecker habitat, and deadwood availability could be simultaneously achieved by permanent set-aside of the stand, whereas substantial losses in particularly three-toed woodpecker habitat and deadwood availability appear inevitable when timber production is also targeted. The situation is further aggravated by findings suggesting that targeting timber production may increase the conflicts between other objectives (Triviño et al., 2017). Naturally, permanent set-aside of large parts of the production forest may not be in the interest of the land-owners. However, as explained above, the selection of alternative management regimes most likely affects the results. Securing high levels of 
ecosystem services and biodiversity while also harvesting for wood may be possible, but require adoption of stand management regimes that differ from the current 'business-as-usual' even more strongly than the alternative regimes included here (for example, selective logging; Kuuluvainen et al., 2012; Pukkala, 2016). The next step is to identify the exact mechanisms causing the losses in ecosystem services to inform development of forestry regimes that minimize these harmful impacts so that better compromises can be achieved. This requires a deeper understanding of the nature of the relationships between the different objectives, including whether they are interacting with each other or just affected by the same drivers (Bennett et al., 2009).

Earlier work has shown that conflicts among timber production and other ecosystem services may be mitigated by optimizing the application of management regimes at a landscape level (Miina et al., 2010; Mönkkönen et al., 2014; Schwenk et al., 2012; Triviño et al., 2015). This may involve, for example, setting aside the stands that are most favorable for biodiversity objectives, and applying intensive management in the stands that are best at producing timber. These types of 'land-sparing' options were explicitly not considered in the present study. The effect of spatial scale and the effects of other spatial factors (e.g. location of demand for the services) on the achievability of good compromise solutions remain questions for future research. Besides spatial, also the time frame of the study and the temporal variation of supply and demand of different ecosystem services should be considered. Here, for example, we considered the supply of each objective averaged over the simulation time, but not its evenness over time. Of particular importance may be, for example, the evenness of timber supply, or the temporal continuity of deadwood resources for biodiversity conservation (Jonsson et al., 2005; Siitonen et al., 2000).

Our study shows that in boreal production forests the conflicts between the primary provisioning service of timber and other benefits are real, severe, and challenging to solve. Research into the processes affecting the supply of different forest ecosystem services may aid in the design of forestry practices and planning management regimes that protect diverse forest benefits. Here, forestry policies may also play an important role. A recent review by Howe et al. (2014) showed that trade-offs among ecosystem services are especially likely to occur when one of the services is a provisioning service and one of the stakeholders involved has a private interest in the benefits. This is exactly the case in privately owned production forests, where the financial gains of the forest owner may contrast with public benefits such as recreational use, water quality regulation, and climate change mitigation. Besides new management practices, new regulations and/or incentives such as certification schemes or payments for ecosystem services (e.g. Patterson and Coelho, 2009) may be required to encourage the adoption of more sustainable management practices and to improve the protection of public interests in boreal production forests. 


\section{Acknowledgments}

We are grateful to the Kone Foundation and to the Academy of Finland (project number 275329 to M. Mönkkönen) for funding. Data was compiled and processed with funding from the Finnish Ministry of Agriculture and Forestry (project 311159). We thank D. Burgas and T. Heinonen for valuable comments and discussions.

\section{Literature cited:}

Albert, C., Aronson, J., Fürst, C., Opdam, P., 2014. Integrating ecosystem services in landscape planning: requirements, approaches, and impacts. Landsc. Ecol. 29, 1277-1285. doi:10.1007/s10980-014-00850

Bennett, E.M., Peterson, G.D., Gordon, L.J., 2009. Understanding relationships among multiple ecosystem services. Ecol. Lett. 12, 1394-404. doi:10.1111/j.1461-0248.2009.01387.x

Biber, P., Borges, J., Moshammer, R., Barreiro, S., Botequim, B., Brodrechtová, Y., Brukas, V., Chirici, G., Cordero-Debets, R., Corrigan, E., Eriksson, L., Favero, M., Galev, E., Garcia-Gonzalo, J., Hengeveld, G., Kavaliauskas, M., Marchetti, M., Marques, S., Mozgeris, G., Navrátil, R., Nieuwenhuis, M., Orazio, C., Paligorov, I., Pettenella, D., Sedmák, R., Smreček, R., Stanislovaitis, A., Tomé, M., Trubins, R., Tuček, J., Vizzarri, M., Wallin, I., Pretzsch, H., Sallnäs, O., 2015. How Sensitive Are Ecosystem Services in European Forest Landscapes to Silvicultural Treatment? Forests 6, 1666-1695. doi:10.3390/f6051666

Bradford, J.B., D'Amato, A.W., 2012. Recognizing trade-offs in multi-objective land management. Front. Ecol. Environ. 10, 210-216. doi:10.1890/110031

Brandt, P., Abson, D.J., DellaSala, D. a., Feller, R., von Wehrden, H., 2014. Multifunctionality and biodiversity: Ecosystem services in temperate rainforests of the Pacific Northwest, USA. Biol. Conserv. 169, 362-371. doi:10.1016/j.biocon.2013.12.003

Clason, A.J., Lindgren, P.M.F., Sullivan, T.P., 2008. Comparison of potential non-timber forest products in intensively managed young stands and mature/old-growth forests in south-central British Columbia. For. Ecol. Manage. 256, 1897-1909. doi:10.1016/j.foreco.2008.07.013

De-Miguel, S., Bonet, J.A., Pukkala, T., Martínez de Aragón, J., 2014. Impact of forest management intensity on landscape-level mushroom productivity: A regional model-based scenario analysis. For. Ecol. Manage. 330, 218-227. doi:10.1016/j.foreco.2014.07.014

Duncker, P.S., Raulund-Rasmussen, K., Gundersen, P., Katzensteiner, K., Jong, J. De, Ravn, H.P., Smith, M., Eckmüllner, O., Spiecker, H., Sp, 2012. How Forest Management affects Ecosystem Services, including Timber Production and Economic Return : Synergies and Trade-Offs. Ecol. Soc. 17, 50.

Edwards, D.P., Gilroy, J.J., Woodcock, P., Edwards, F.A., Larsen, T.H., Andrews, D.J.R., Derhé, M.A., Docherty, T.D.S., Hsu, W.W., Mitchell, S.L., Ota, T., Williams, L.J., Laurance, W.F., Hamer, K.C., Wilcove, D.S., 2014. Land-sharing versus land-sparing logging: reconciling timber extraction with biodiversity conservation. Glob. Chang. Biol. 20, 183-91. doi:10.1111/gcb.12353

Edwards, D.P., Tobias, J.A., Sheil, D., Meijaard, E., Laurance, W.F., 2014. Maintaining ecosystem function and services in logged tropical forests. Trends Ecol. Evol. 29, 511-520. doi:10.1016/j.tree.2014.07.003

Fayt, P., Machmer, M.M., Steeger, C., 2005. Regulation of spruce bark beetles by woodpeckers-a literature review. For. Ecol. Manage. 206, 1-14. doi:10.1016/j.foreco.2004.10.054

Finnish Forest Centre, 2016. Suomen metsäkeskuksen metsävaratiedon laatuseloste. 
Gamfeldt, L., Snäll, T., Bagchi, R., Jonsson, M., Gustafsson, L., Kjellander, P., Ruiz-Jaen, M.C., Fröberg, M., Stendahl, J., Philipson, C.D., Mikusiński, G., Andersson, E., Westerlund, B., Andrén, H., Moberg, F., Moen, J., Bengtsson, J., 2013. Higher levels of multiple ecosystem services are found in forests with more tree species. Nat. Commun. 4, 1340. doi:10.1038/ncomms2328

Gao, T., Nielsen, A.B., Hedblom, M., 2015. Reviewing the strength of evidence of biodiversity indicators for forest ecosystems in Europe. Ecol. Indic. 57, 420-434. doi:10.1016/j.ecolind.2015.05.028

Howe, C., Suich, H., Vira, B., Mace, G.M., 2014. Creating win-wins from trade-offs? Ecosystem services for human well-being: A meta-analysis of ecosystem service trade-offs and synergies in the real world. Glob. Environ. Chang. 28, 263-275. doi:10.1016/j.gloenvcha.2014.07.005

Hynynen, J., Ojansuu, R., Hökkä, H., Siipilehto, J., Salminen, H., Haapala, P., 2002. Models for predicting stand development in MELA System. Finnish Forest Research Institute. Research Papers. 835.

Hyvän metsänhoidon suositukset, 2006. Metsätalouden kehittämiskeskus Tapio. Metsäkustannus.

Jonsson, B.G., Kruys, N., Ranius, T., 2005. Ecology of Species Living on Dead Wood - Lessons for Dead Wood Management. Silva Fenn. 39.

Kremen, C., 2015. Reframing the land-sparing/land-sharing debate for biodiversity conservation. Ann. N. Y. Acad. Sci. n/a-n/a. doi:10.1111/nyas.12845

Kremen, C., 2005. Managing ecosystem services: what do we need to know about their ecology? Ecol. Lett. 8, 468-79. doi:10.1111/j.1461-0248.2005.00751.x

Kuuluvainen, T., Tahvonen, O., Aakala, T., 2012. Even-aged and uneven-aged forest management in boreal Fennoscandia: a review. Ambio 41, 720-37. doi:10.1007/s13280-012-0289-y

Lassauce, A., Paillet, Y., Jactel, H., Bouget, C., 2011. Deadwood as a surrogate for forest biodiversity: Metaanalysis of correlations between deadwood volume and species richness of saproxylic organisms. Ecol. Indic. 11, 1027-1039. doi:10.1016/j.ecolind.2011.02.004

Lindner, M., Maroschek, M., Netherer, S., Kremer, A., Barbati, A., Garcia-Gonzalo, J., Seidl, R., Delzon, S., Corona, P., Kolström, M., Lexer, M.J., Marchetti, M., 2010. Climate change impacts, adaptive capacity, and vulnerability of European forest ecosystems. For. Ecol. Manage. 259, 698-709. doi:10.1016/j.foreco.2009.09.023

Liski, J., Pussinen, A., Pingoud, K., Mäkipää, R., Karjalainen, T., 2001. Which rotation length is favourable to carbon sequestration? Can. J. For. Res. 31, 2004-2013. doi:10.1139/x01-140

Mäkelä, H., Pekkarinen, A., 2004. Estimation of forest stand volumes by Landsat TM imagery and standlevel field-inventory data. For. Ecol. Manage. 196, 245-255. doi:10.1016/j.foreco.2004.02.049

Maskell, L.C., Crowe, A., Dunbar, M.J., Emmett, B., Henrys, P., Keith, A.M., Norton, L.R., Scholefield, P., Clark, D.B., Simpson, I.C., Smart, S.M., 2013. Exploring the ecological constraints to multiple ecosystem service delivery and biodiversity. J. Appl. Ecol. 50, 561-571. doi:10.1111/1365-2664.12085

Mazziotta, A., Podkopaev, D., Triviño, M., Miettinen, K., Pohjanmies, T., Mönkkönen, M., 2017. Quantifying and resolving conservation conflicts in forest landscapes via multiobjective optimization. Silva Fenn. 51, 1-19. doi:10.14214/sf.1778

MEA, 2005. Ecosystems and Human Well-being: Synthesis. Island Press, Washington, DC.

Miina, J., Hotanen, J., Salo, K., 2009. Modelling the Abundance and Temporal Variation in the Production of Bilberry (Vaccinium myrtillus L.) in Finnish mineral soil forests. Silva Fenn. 43, 577-593.

Miina, J., Pukkala, T., Hotanen, J.-P., Salo, K., 2010. Optimizing the joint production of timber and bilberries. For. Ecol. Manage. 259, 2065-2071. doi:10.1016/j.foreco.2010.02.017

Moen, J., Rist, L., Bishop, K., Chapin, F.S., Ellison, D., Kuuluvainen, T., Petersson, H., Puettmann, K.J., Rayner, J., Warkentin, I.G., Bradshaw, C.J.A., 2014. Eye on the Taiga: Removing Global Policy Impediments to Safeguard the Boreal Forest. Conserv. Lett. 7, 408-418. doi:10.1111/conl.12098 
Mönkkönen, M., Juutinen, A., Mazziotta, A., Miettinen, K., Podkopaev, D., Reunanen, P., Salminen, H., Tikkanen, O.-P., 2014. Spatially dynamic forest management to sustain biodiversity and economic returns. J. Environ. Manage. 134, 80-9. doi:10.1016/j.jenvman.2013.12.021

Nybakken, L., Selås, V., Ohlson, M., 2013. Increased growth and phenolic compounds in bilberry (Vaccinium myrtillus L.) following forest clear-cutting. Scand. J. For. Res. 28, 319-330. doi:10.1080/02827581.2012.749941

Pakkala, T., 2012. Spatial ecology of breeding birds in forest landscapes : an indicator species approach. University of Eastern Finland.

Pan, Y., Birdsey, R.A., Fang, J., Houghton, R., Kauppi, P.E., Kurz, W.A., Phillips, O.L., Shvidenko, A., Lewis, S.L., Canadell, J.G., Ciais, P., Jackson, R.B., Pacala, S.W., McGuire, A.D., Piao, S., Rautiainen, A., Sitch, S., Hayes, D., 2011. A large and persistent carbon sink in the world's forests. Science (80-. ). 333, 988993. doi:10.1126/science.1201609

Patterson, T.M., Coelho, D.L., 2009. Ecosystem services: Foundations, opportunities, and challenges for the forest products sector. For. Ecol. Manage. 257, 1637-1646. doi:10.1016/j.foreco.2008.11.010

Peura, M., Triviño, M., Mazziotta, A., Podkopaev, D., Juutinen, A., Mönkkönen, M., 2016. Managing boreal forests for the simultaneous production of collectable goods and timber revenues. Silva Fenn. 50, 117. doi:10.14214/sf.1672

Pohjanmies, T., Triviño, M., Le Tortorec, E., Mazziotta, A., Snäll, T., Mönkkönen, M., 2017. Impacts of forestry on boreal forests: An ecosystem services perspective. Ambio. doi:10.1007/s13280-017-0919-5

Pukkala, T., 2016. Which type of forest management provides most ecosystem services? For. Ecosyst. 3, 9. doi:10.1186/s40663-016-0068-5

Rassi, P., Hyvärinen, E., Juslén, A., Mannerkoski, I. (Eds.), 2010. The 2010 Red List of Finnish Species. Ympäristöministeriö \& Suomen ympäristökeskus, Helsinki.

Rodríguez, J.P., Beard, T.D.J., Bennett, E.M., Cumming, G.S., Cork, S.J., Agard, J., Dobson, A.P., Peterson, G.D., 2006. Trade-offs across Space, Time, and Ecosystem Services. Ecol. Soc. 11, 28.

Salminen, H., Lehtonen, M., Hynynen, J., 2005. Reusing legacy FORTRAN in the MOTTI growth and yield simulator. Comput. Electron. Agric. 49, 103-113. doi:10.1016/j.compag.2005.02.005

Schwenk, W.S., Donovan, T.M., Keeton, W.S., Nunery, J.S., 2012. Carbon storage, timber production, and biodiversity: comparing ecosystem services with multi-criteria decision analysis. Ecol. Appl. 22, 16121627. doi:10.1890/11-0864.1

Seidl, R., Spies, T. a., Peterson, D.L., Stephens, S.L., Hicke, J. a., 2016. REVIEW: Searching for resilience: addressing the impacts of changing disturbance regimes on forest ecosystem services. J. Appl. Ecol. 53, 120-129. doi:10.1111/1365-2664.12511

Siitonen, J., 2001. Forest Management, coarse woody debris and saproxylic organisms: Fennoscandian boreal forests as an example. Ecol. Bull. 49, 10-41.

Siitonen, J., Martikainen, P., Punttila, P., Rauh, J., 2000. Coarse woody debris and stand characteristics in mature managed and old-growth boreal mesic forests in southern Finland. For. Ecol. Manage. 128, 211-225. doi:10.1016/S0378-1127(99)00148-6

Tikkanen, O.-P., Martikainen, P., Hyvarinen, E., Junninen, K., Kouki, J., 2006. Red-listed boreal forest species of Finland: associations with forest structure, tree species, and decaying wood. Ann. Zool. Fennici 43, 373-383.

Triviño, M., Juutinen, A., Mazziotta, A., Miettinen, K., Podkopaev, D., Reunanen, P., Mönkkönen, M., 2015. Managing a boreal forest landscape for providing timber, storing and sequestering carbon. Ecosyst. Serv. 14, 179-189. doi:10.1016/j.ecoser.2015.02.003

Triviño, M., Pohjanmies, T., Mazziotta, A., Juutinen, A., Podkopaev, D., Le Tortorec, E., Mönkkönen, M., 
2017. Optimizing management to enhance multifunctionality in a boreal forest landscape. J. Appl. Ecol. 54, 61-70. doi:10.1111/1365-2664.12790

Vaara, M., Saastamoinen, O., Turtiainen, M., 2013. Changes in wild berry picking in Finland between 1997 and 2011. Scand. J. For. Res. 28, 586-595. doi:10.1080/02827581.2013.786123

Zanchi, G., Belyazid, S., Akselsson, C., Yu, L., 2014. Modelling the effects of management intensification on multiple forest services: a Swedish case study. Ecol. Modell. 284, 48-59. doi:10.1016/j.ecolmodel.2014.04.006 
Tähti Pohjanmies, María Triviño, Eric Le Tortorec, Hannu Salminen, Mikko Mönkkönen. 2016. Conflicting objectives in production forests pose a challenge for forest management.

\section{Appendix A: Details on the forest growth simulations}

We simulated the development of the forest stands with the MOTTI stand simulator (Hynynen et al., 2002; Salminen et al., 2005). MOTTI projects the development of a stand based on its initial characteristics and the forestry operations applied during the simulation. The system core comprises distance-independent tree-level models for growth and mortality operating at 1-5 year steps. The parameterization of tree growth in MOTTI is based on extensive field data from sample plots on forestry land in Finland and representing prevailing growing conditions and management regimes. The uncertainty of predictions increases when individual models are used outside their intended range. This may be the case when simulating the most extreme options.

The stand development was simulated for 50 years into the future. We selected the simulation time of 50 years as it is a compromise between the typical rotation length in the area and the validity of MOTTI simulations.

It should be noted that the effects of climate change on forest growth were not taken into account in the simulations. Climate change is expected to have significant effects on forest growth; however, these are expected to become evident only towards the end of the 21st century and remain inconsequential within the next 50 years (Kellomäki et al., 2008). For this reason we did not take them into account in the simulations.

Appendix B: Additional details on the calculations of the ecosystem service and biodiversity indicators Bilberry production

Bilberry (Vaccinium myrtillus) production data was taken from Peura et al. (2016), where bilberry production was estimated using the models and methods of Miina et al. (2010, 2009). These models predict bilberry coverage and yield based on stand characteristics (e.g. dominant tree species, stand age, and stand basal area).

\section{Carbon storage}

The carbon storage data was taken from Triviño et al. (2015). Here, carbon storage was calculated as the amount of carbon stored in living trees, deadwood, and extracted timber at a given time (for each time 
step of the simulation period). The total tree biomass (living, extracted, and cutting residues) was estimated from the MOTTI predictions of timber volume, and the amount of carbon in the biomass was calculated by multiplying it by 0.5 . For deadwood and cutting residues, the decaying rate of the biomass was taken into account. For further details, see Triviño et al. (2015).

\section{Habitat availability for three-toed woodpecker}

Estimates of habitat availability for three-toed woodpecker (Picoides tridactylus) were taken from Mönkkönen et al. (2014). Three-toed woodpecker prefers mature forests with abundant fresh deadwood to use as feeding and nesting resources. Mönkkönen et al. (2014) calculated estimates of habitat availability for the species with a model that estimates a habitat suitability index related to the probability of presence of the species. It is estimated based on the total basal area of recently died trees $(B A)$ and the total stem volume of living trees $(V)$. The model combines the logistic regression model constructed by Roberge et al. (2008) linking $B A$ and occurrence of the species, and threshold values for site quality measured as $V$ suggested by Pakkala et al. (2002). Mönkkönen et al. (2014) calculated the habitat suitability index as the product of these two models, so that the value of the index varies between zero and one. It gets a value of zero if $V$ is $<60 \mathrm{~m}^{3}$, increases as $B A$ and $V$ increase, and is close to one when $B A$ is $>2.5 \mathrm{~m}^{2}$ ha ${ }^{-1}$ and $V$ is $>$ $200 \mathrm{~m}^{3}$.

\section{Availability of deadwood resources}

The MOTTI simulations produce estimates of the volume of deadwood $(\mathrm{kg} / \mathrm{ha})$ in a stand at each time step. Deadwood volume is estimated separately for 20 different deadwood types, given by four tree species $\times$ five decay stages. The four tree species are the four most dominant species in the region: pine (Pinus sylvestris), spruce (Picea abies), and birch (Betula pendula and Betula pubescens). The five decay stages are based on Mäkinen et al. (2006) and are the following ones: 1) recently dead tree; 2) weakly decayed; 3 ) medium decayed; 4) very decayed; and 5) almost decomposed. We measured the diversity of deadwood using Simpson's diversity index (D) calculated over the 20 deadwood types. The availability of deadwood resources $(D W A)$ in a stand was then calculated as the product of the total volume of deadwood and its diversity:

$D W A=(1-D) \sum_{i=1}^{20}$ Voli

\section{Appendix C: Results for the full data set}

When the stands in which the same management regime could maximize both objectives were not excluded, the pairwise tolerance indices were naturally higher and the compromise solutions better, and 
this was especially evident for the pairs of objectives which were the most compatible (i.e., those among carbon storage, TTWO habitat, and deadwood availability). Still, the conflicts were the strongest between timber production and the other objectives, and the second strongest for pairs involving bilberry production (Figure C1). Conversely, the tolerance indices were high (median values of $100 \%$, i.e. no conflict in majority of the stands) for all pairs among carbon storage, three-toed woodpecker habitat, and deadwood availability (Figure $\mathrm{C} 1$ ). The goodness of the compromise solutions followed the same patterns: the most severe conflicts could not be solved with balanced outcomes, whereas the compromises were very good when the conflicts between the objectives were weak to begin with (Figure C2).
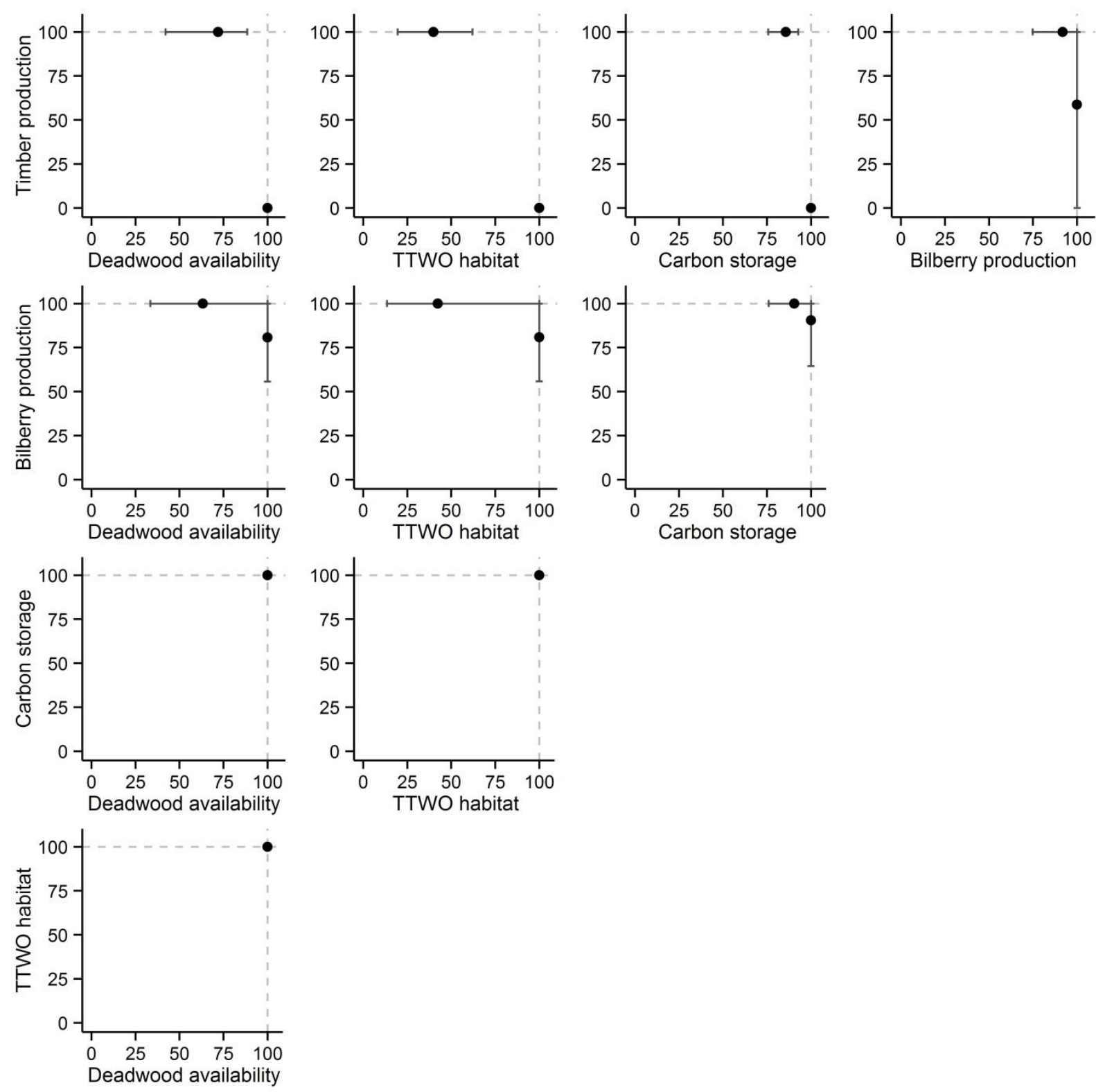

Figure C1. Pairwise tolerance indices for all pairs of objectives. The black points show the median values and the error bars the second and third quartiles of stand-level values. The tolerance indices are expressed 
as percentage of the maximal achievable value; units on all axes are thus percentages (\%). Dashed grey lines have been added to all plots at $y=100 \%$ and $x=100 \%$ for graphical comparison. TTWO stands for three-toed woodpecker.
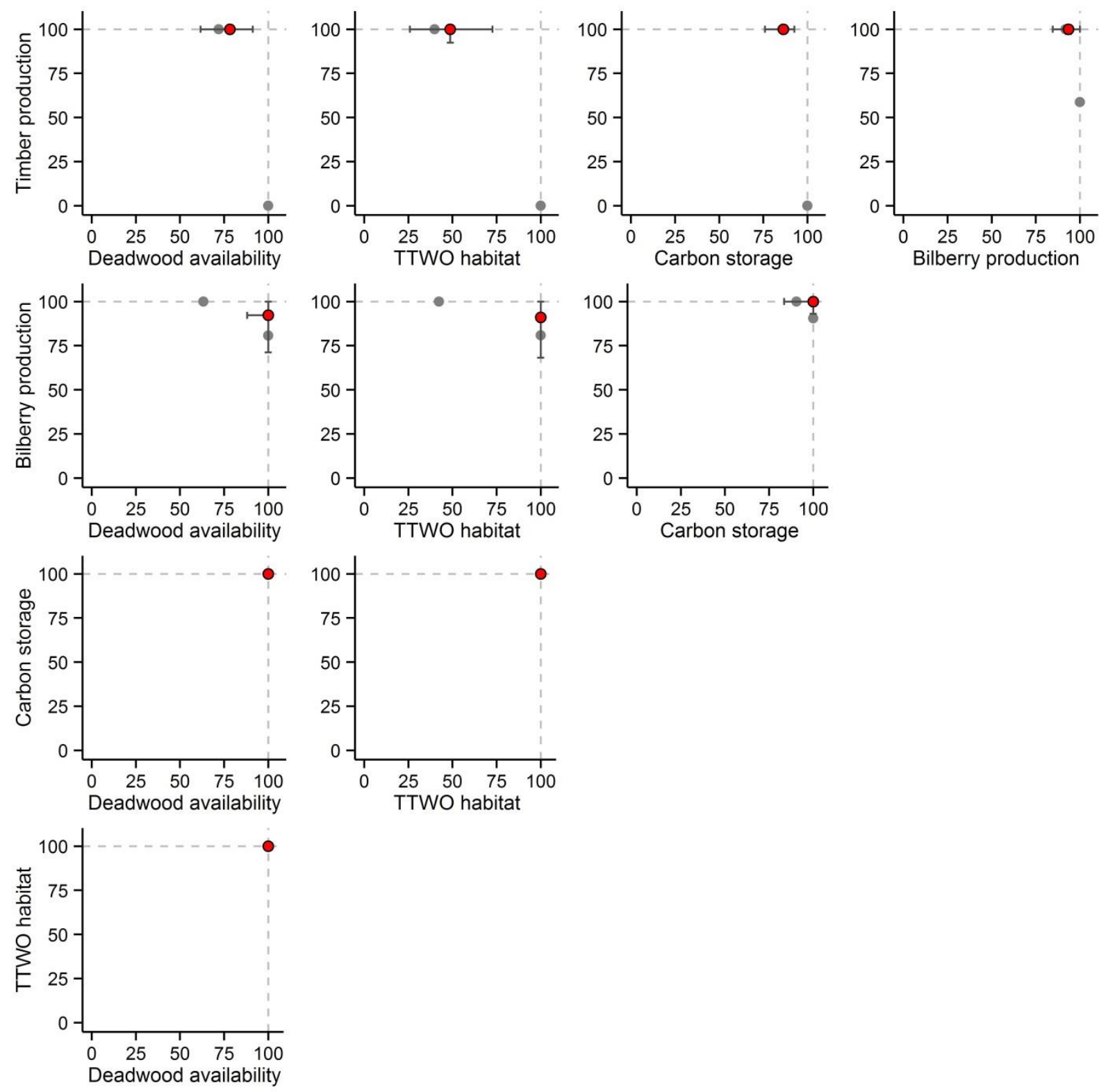

Figure C2. Compromise solutions for all pairs of objectives. In each plot, the red point shows the median value and the error bars the second and third quartiles of stand-level values of the two objectives under the compromise solution. The two grey points show the median values of the tolerance indices for comparison (same as in Figure S1). Units on all axes are percentages (\%). Dashed grey lines have been added to all plots at $y=100 \%$ and $x=100 \%$ for graphical comparison. The closer to the point $(100,100)$ the compromise is, the better it is in terms of the two objectives. TTWO stands for three-toed woodpecker.

\section{Literature cited:}


Hynynen, J., Ojansuu, R., Hökkä, H., Siipilehto, J., Salminen, H., Haapala, P., 2002. Models for predicting stand development in MELA System. Finnish Forest Research Institute. Research Papers 835.

Kellomäki, S., Peltola, H., Nuutinen, T., Korhonen, K.T., Strandman, H., 2008. Sensitivity of managed boreal forests in Finland to climate change, with implications for adaptive management. Philos. Trans. R. Soc. Lond. B. Biol. Sci. 363, 2341-2351. doi:10.1098/rstb.2007.2204

Mäkinen, H., Hynynen, J., Siitonen, J., Sievänen, R., 2006. Predicting the decomposition of Scots pine, Norway spruce, and birch stems in Finland. Ecol. Appl. 16, 1865-1879.

Miina, J., Hotanen, J.-P, Salo, K., 2009. Modelling the Abundance and Temporal Variation in the Production of Bilberry (Vaccinium myrtillus L.) in Finnish mineral soil forests. Silva Fenn. 43, 577-593.

Miina, J., Pukkala, T., Hotanen, J.-P., Salo, K., 2010. Optimizing the joint production of timber and bilberries. For. Ecol. Manage. 259, 2065-2071. doi:10.1016/j.foreco.2010.02.017

Mönkkönen, M., Juutinen, A., Mazziotta, A., Miettinen, K., Podkopaev, D., Reunanen, P., Salminen, H., Tikkanen, O.-P., 2014. Spatially dynamic forest management to sustain biodiversity and economic returns. J. Environ. Manage. 134, 80-89. doi:10.1016/j.jenvman.2013.12.021

Pakkala, T., Hanski, I., Tomppo, E., 2002. Spatial ecology of the three-toed woodpecker in managed forest landscapes. Silva Fenn. 36, 279-288.

Peura, M., Triviño, M., Mazziotta, A., Podkopaev, D., Juutinen, A., Mönkkönen, M., 2016. Managing boreal forests for the simultaneous production of collectable goods and timber revenues. Silva Fenn. 50, 117. doi:10.14214/sf.1672

Roberge, J.M., Angelstam, P., Villard, M.A., 2008. Specialised woodpeckers and naturalness in hemiboreal forests - Deriving quantitative targets for conservation planning. Biol. Conserv. 141, 997-1012. doi:10.1016/j.biocon.2008.01.010

Salminen, H., Lehtonen, M., Hynynen, J., 2005. Reusing legacy FORTRAN in the MOTTI growth and yield simulator. Comput. Electron. Agric. 49, 103-113. doi:10.1016/j.compag.2005.02.005

Triviño, M., Juutinen, A., Mazziotta, A., Miettinen, K., Podkopaev, D., Reunanen, P., Mönkkönen, M., 2015. Managing a boreal forest landscape for providing timber, storing and sequestering carbon. Ecosyst. Serv. 14, 179-189. doi:10.1016/j.ecoser.2015.02.003 